\title{
Gene expression changes in the salivary glands of Anopheles coluzzii elicited by Plasmodium berghei infection
}

Renato Pinheiro-Silva', Lara Borges ${ }^{1,7}$, Luís Pedro Coelho ${ }^{2}$, Alejandro Cabezas-Cruz ${ }^{3,4}$, James J. Valdés ${ }^{5}$, Virgílio do Rosário ${ }^{1}$, José de la Fuente ${ }^{4,6}$ and Ana Domingos ${ }^{1,7^{*}}$

\begin{abstract}
Background: Malaria is a devastating infectious disease caused by Plasmodium parasites transmitted through the bites of infected Anopheles mosquitoes. Salivary glands are the only mosquito tissue invaded by Plasmodium sporozoites, being a key stage for the effective parasite transmission, making the study of Anopheles sialome highly relevant.

Methods: RNA-sequencing was used to compare differential gene expression in salivary glands of uninfected and Plasmodium berghei-infected Anopheles coluzzii mosquitoes. RNA-seq results were validated by quantitative RT-PCR. The transmembrane glucose transporter gene AGAP007752 was selected for functional analysis by RNA interference. The effect of gene silencing on infection level was evaluated. The putative function and tertiary structure of the protein was assessed.

Results: RNA-seq data showed that 2588 genes were differentially expressed in mosquitoes salivary glands in response to $P$. berghei infection, being 1578 upregulated and 1010 downregulated. Metabolism, Immunity, Replication/Transcription/Translation, Proteolysis and Transport were the mosquito gene functional classes more affected by parasite infection. Endopeptidase coding genes were the most abundant within the differentially expressed genes in infected salivary glands $(P<0.001)$. Based on its putative function and expression level, the transmembrane glucose transporter gene, AGAP007752, was selected for functional analysis by RNA interference. The results demonstrated that the number of sporozoites was $44.3 \%$ lower in mosquitoes fed on infected mice after AGAPP007752 gene knockdown when compared to control $(P<0.01)$.

Conclusions: Our hypothesis is that the protein encoded by the gene AGAPP007752 may play a role on An. coluzzii salivary glands infection by Plasmodium parasite, working as a sporozoite receptor and/or promoting a favorable environment for the capacity of sporozoites.
\end{abstract}

Keywords: Anopheles coluzzii, Salivary glands, Plasmodium berghei, Sporozoite, RNA-seq, Glucose transporter, RNAi

\section{Background}

Malaria is a mosquito-borne infectious disease caused by Plasmodium parasites, with 200 million cases estimated to occur around the world, each year. Human malaria is transmitted exclusively through the bites of infected Anopheles mosquitoes, being Anopheles coluzzii the main vector in Africa [1].

\footnotetext{
* Correspondence: adomingos@ihmt.unl.pt

'Instituto de Higiene e Medicina Tropical (IHMT), Lisbon, Portugal

'Global Health and Tropical Medicine (GHMT), Instituto de Higiene e Medicina Tropical (IHMT), Lisbon, Portugal

Full list of author information is available at the end of the article
}

Transmission of Plasmodium parasites is initiated through the ingestion of gametocytes by female mosquitoes feeding on an infected individual. Male and female gametes produce, after fertilization, zygotes that differentiate into motile ookinetes and invade the midgut epithelium. Ookinetes differentiate into oocysts after emerging on the hemocoel side, mature and release thousands of sporozoites into the hemolymph. When infected mosquitoes bite an individual and release some of these sporozoites, the transmission cycle is completed [2].

Of all mosquito tissues and cell types that the sporozoites come in contact with, they only invade the salivary 
glands (SG) which, together with mosquito saliva, can be considered central to the interaction between parasite, vector and mammalian hosts [3]. The sporozoite attaches to the basal lamina and subsequently binds to the basolateral membrane of the epithelial cells. This attachment and invasion are facilitated by the interaction between sporozoite and SG surface molecules [4], meaning the invasion depends on parasite recognition of mosquito SG surface components [5]. The maturation of sporozoite in the SGs is a key stage for the effective transmission, increasing sporozoite ability to infect vertebrate hepatocytes [3].

Previous studies have demonstrated that carbohydrates receptors may have an important role on parasite-vector interaction [6-9]. Although the relation between oocysts and carbohydrates has been reported $[6,7]$, their interactions with SG remains unclear.

In mosquito, as well as in other arthropods, RNAsequencing (RNA-seq) and RNA interference (RNAi) have been applied for de novo transcriptome assemblies and expression profiles obtained at a specific condition [10-12] and for the study of gene function [13-16].

The publication of genome sequences from several arthropod vector species $[17,18]$ combined with transcriptomics and proteomics analyses of their SG extracts [19-23] revealed new insights into the diversity of salivary components in these organisms. The SG transcriptome and proteome of $A n$. coluzzii have been characterized, providing a full description of the salivary proteins in this species [24]. However, despite the fact that the genome of $A n$. coluzzii has already been sequenced [17], a significant number of genes still do not have a putative function assigned and, although there are reports concerning the characterization of mosquito SG genes [25-27], little is known about SG protein-sporozoite interactions.

In the absence of a licensed malaria vaccine and facing an increase in parasite resistance to new combined drugs and to insecticides used for indoor spraying and in bed nets, the development of complementary measures for vector control are highly needed [28]. Preliminary results obtained in arthropod vectors with impact on both human and animal health revealed that protective antigens can be used for the development of new tools against both vectors and pathogens [29-33].

Herein, we report a RNA-seq analysis of differential gene expression in the salivary glands of $A n$. coluzzii elicited by $P$. berghei infection. A catalogue of transcripts was produced and analyzed, providing a valuable platform for future research. Further, gene expression was experimentally validated. A SG membrane transporter gene exhibiting the highest expression level regarding the transport functional class was chosen for functional analysis and the effect of gene knockdown on malaria parasite levels was further evaluated. A three dimensional model was elaborated and discussed. These findings will improve our understanding of mosquito SG infection process, contributing to the development of new measures for malaria control.

\section{Methods}

\section{Ethics statement}

The maintenance and care of experimental animals was carried out in accordance to the Europe Directive 86/ 609/EEC and Portuguese law (Decreto-Lei 129/92) recommendations and protocol approved by the Divisão Geral de Alimentação e Veterinária (DGAV), Portugal, under Portaria $8 n^{\circ} 1005 / 92$ from 23rd October. Authors directly involved with animal manipulation were licensed to conduct research using laboratory animals.

\section{Mosquito rearing}

An. coluzzii s.s (An. gambiae molecular M form) of the Yaoundé strain mosquitoes were obtained from the Institute of Hygiene and Tropical Medicine insectary, reared at $27{ }^{\circ} \mathrm{C}, 70 \%$ relative humidity under a $12 \mathrm{~h}$ light/dark photoperiod and fed ad libitum on a $10 \%$ glucose solution. The adult female mosquitoes used in these experiments were aged between 3-5 days.

\section{$P$. berghei GFP infections}

Mosquitos were infected with $P$. berghei parasites (strain ANKA), which constitutively express green fluorescent protein (GFP) [34]. Parasites were maintained by serial passage in 3- to 4-week-old female CD1 mice (Mus musculus) from frozen stocks. Parasitaemia were determined 2-3 days after passage using light microscopy by methanol fixation of air-dried blood smears and stained with $20 \%(w / v)$ Giemsa solution. Mosquitos were allowed to feed on mice when parasitaemia was between 4 and $6 \%$ and 4-5 exflagellations/field were observed. Female mosquitoes (100 per group) were fed on anesthetized mice during 40-45 min. Non-fed females were removed from the cage. Infected and control (fed on uninfected mice) mosquitoes were kept at $21{ }^{\circ} \mathrm{C}$ and $70 \%$ humidity to allow parasite development. Midguts were dissected 8-9 days post-blood meal (PBM) to confirm the presence of oocysts, using fluorescent microscopy.

\section{RNA extraction}

Mosquitos were cold anaesthetized on ice and placed onto a glass slide in phosphate-buffered saline (PBS). To obtain the SG free of other tissues, legs and the head were first pulled off using forceps, the thorax was pushed down and the connection between these tissues and the SG was cut using a needle-tip, under a stereoscopic microscope at 4X magnification (Motic SMZ-171B, China). SG were dissected 18-19 days PBM, collected in phosphate buffer containing DEPC (DEPC-PBS) before 
transferred to RNA later (Ambion, Austin, TX, USA) and frozen at $-80{ }^{\circ} \mathrm{C}$ until utilization. Total RNA was extracted using the RNeasy kit (Qiagen, Inc., Valencia, California, USA). After extraction, the RNA samples were quantified and analyzed for purity on a ND-1000 Spectrophotometer (NanoDrop ND1000, Thermo Fisher Scientific, Whaltman, MA). Extracted RNA obtained from six pools of SG (three from infected mosquitoes and three from uninfected mosquitoes) was used for RNA-seq. To obtain the quantity needed to perform RNA-seq, the samples were pooled, resulting in one biological replicate of SG infected mosquitoes and one biological replicate of SG uninfected mosquitoes.

\section{RNA-seq library preparation and sequencing}

RNA quality and integrity were checked on an Agilent 2100 Bioanalyzer Nano Chip (Agilent Technologies, Santa Clara, CA, USA). The RNA-seq library preparation and sequencing were performed according with Ayllón and co-workers (2015) [35], using total RNA and Illumina TruSeq $^{\text {in }}$ RNA Sample Prep Kit v2 (Illumina, San Diego, CA, USA), following the manufacturer's protocol.

The quality of the FASTQ sequences was enhanced by trimming off low-quality bases using the "Trim sequences" option of the CLC Genomics Workbench version 5.5.1 (CLC Bio, Cambridge, MA, USA). The quality-filtered sequence reads are used for further analysis with the CLC Genomics Workbench. First, an alignment against the $A n$. coluzzii genome reference (ftp://ftp.ensemblgenomes.org/ $\mathrm{pub} /$ metazoa/release-15/fasta/anopheles_gambiae/dna/) and calculation of the expression values was performed using the "RNA-seq" option. The comparison of expression values and statistical analysis was performed with the "Expression analysis" option. To normalize for the difference in number of mapped reads and transcript length, quality control was performed, comparing the overall distributions of the RPKM (reads per kilobase of exon model per Million mapped reads) expression between samples and groups [36]. Finally, samples were clustered into groups using a hierarchical clustering approach. The hierarchical structure was chosen because the Bayesian model-based approach reduces the bias caused by the absence of the biological replicates, increasing the precision of differentially expressed genes [37]. $P$-value calculation of the Z-test was based on the raw counts (total exon reads per gene). Genes were considered significantly differentially expressed if the $P$-value was below 0.05 and the fold - change greater than one standard deviations above or below the average fold change across all genes. To analyze the statistically represented gene classes or categories, the g: Profiler web server (http://biit.cs.ut.ee/gprofiler/) was used.

The gene selected for RNA interference assay was filtered using location predictors WoLF PSORT [38] and MultiLoc2 [39].

\section{Validation of RNA-seq data}

A total of eighteen transcripts identified by RNA-seq as being differentially regulated and belonging to different functional classes were chosen based on fold-change value (Additional file 1: Table S1) to confirm RNA-seq results by quantitative real-time-Polymerase Chain Reaction (qPCR). Total RNA extracted from infected and non-infected An. coluzzii SG (100 per group) was used to synthesize cDNA.

The Primer 3 platform (http://bioinfo.ut.ee/primer3$0.4 .0 /$ ) was used to design all primers (Additional file 2; Table S2). Gene expression was assessed by $\mathrm{iQ}^{\mathrm{ma}} \mathrm{SYBR}^{\circ}$ Green supermix for qPCR (Bio-Rad, Hercules, CA, USA) in a total volume of $20 \mu \mathrm{l}$, using the $\mathrm{iCycler}_{\mathrm{iQ}}^{\mathrm{im}}$ (Bio-Rad, Hercules, CA, USA). PCR involved an initial denaturation at $95{ }^{\circ} \mathrm{C}$ for $10 \mathrm{~min}, 40$ cycles of $10 \mathrm{sec}$ at $95^{\circ} \mathrm{C}, 45 \mathrm{sec}$ at the appropriate annealing temperature for each set of primers (Additional file 2: Table S2). Fluorescence readings were taken at $62{ }^{\circ} \mathrm{C}$ after each cycle. A final extension at $72{ }^{\circ} \mathrm{C}$ for 5 min was completed before deriving a melting curve $\left(60-95{ }^{\circ} \mathrm{C}\right)$ to determinate the quality of the amplicon. Relative expression results were normalized with An. coluzzii ribosomal protein S7 (Vectorbase: AGAP010592) as internal standard and analyzed by the 2 delta Ct $(\Delta \Delta \mathrm{Ct})$ method [40]. Three biological replicates with independent preparations of total RNA were performed for each gene.

Pearson's correlation was used to compare the results obtained in both RNA-seq and qPCR analyzes.

\section{Gene silencing assays}

RNAi-mediated gene-silencing assays were performed to evaluate the effect of AGAP007752 gene knockdown on $P$. berghei-infected An. coluzzii mosquitoes.

Specific primers containing T7 promoter sequences at the $5^{\prime}$-end were synthesized (Additional file 3: Table S3) and dsRNA produced using the MEGAscript T7 kit (Ambion, Austin, TX, USA), according to manufacturer's instructions. An exogenous gene, mouse beta-2microglobulin ( $\beta 2 M)$ (GenBank: NM_009735) was used as control for the silencing experiments. The dsRNA was purified, diluted in sterile water to a concentration of $4 \mu \mathrm{g} / \mathrm{ml}$ and quality was assessed by spectrometry and agarose gel. For gene knockdown, we perform three experiments of $300 P$. berghei infected female mosquitoes (three to five- days-old) for each gene. Fourteen days PBM, cold anesthetized mosquitoes were injected intrathoraxically with $69 \mathrm{nl}(4 \mu \mathrm{g} / \mathrm{ml})$ of dsRNA using a nano-injector (Nanoject, Drummond Scientific, Broomall, PA, USA). The control group was injected with ds $\beta 2 M$. Quantitative RT-PCR was used to verify the silencing effect. The unpaired two-tailed $t$-test was used to compare the different experimental groups. 


\section{Sporozoite quantification}

SG were dissected 3-4 days post injection (18-19 PBM) and pools of 15-20 SG per treatment were used to perform sporozoite quantification. Each SG pool was homogenized in a total volume of $100 \mu \mathrm{l}$ of phosphatebuffered saline using a mini glass tissue homogenizer (Kontes Glass Co., Vineland, NJ, USA). Sporozoites were counted by light microscopy using a hemocytometer [25]. Sporozoites quantification was performed using three independent biological replicates.

\section{Phylogenetic analysis}

Sequences were aligned with the MUSCLE (v3.7) program, configured for highest accuracy [41] and poorly aligned and unsupported regions were removed with Gblocks (v 0.91b) [42]. The maximum likelihood method, implemented in the PhyML programme (v3.0 aLRT), was used to reconstruct the phylogenetic tree [43, 44]. Reliability for internal branches was assessed using the bootstrapping method (1000 bootstrap replicates). For the Bayesian analysis we used MrBayes (v3.2.2) implementing a proportion of invariable sites and gamma-distributed rate variation across sites $(\mathrm{I}+\mathrm{G})$ with a WAG amino acid substitution model. Two independent runs were executed, each with four Markov Chain Monte Carlo (MCMC) of $50,000,000$ generations, sampling every 1000th generation (this resulted in a StDev $<0.001$ ). The two phylogenetic analyses agreed on tree topology; therefore, bootstrap values and posterior probabilities were included in a single tree. Graphical representation and editing of the phylogenetic tree was performed with TreeDyn (v 198.3) [45].

\section{Tertiary modelling and induced-fit ligand docking}

To approximate an accurate tertiary model of the $A n$. coluzzii protein, we used several protein structure prediction servers, namely FOLDpro [46], I-TASSER [47], 3DJigsaw, LOOPP [48], Rosetta [49], Phyre2 [50] and SwissModel [51]. To assess the quality of the output models and to choose the top candidates, we used Resprox [52], Qmean [53], ModFOLD [54]. A consensus from all three quality assessment servers agreed that the Rosetta models were the most adequate. We then manually inspected the top three Rosetta models to determine any unresolved secondary structures (i.e., $\alpha$-helices). The top candidate was refined via minimization and optimization of the hydrogen-bond network by means of side chain sampling using the Schrodinger's Maestro Protein Preparation Wizard [55]. Briefly, the Protein Preparation Wizard analyzes the structure to build a cluster of hydrogen-bonds and with the highest degree of sampling, the algorithm performs 100000 Monte Carlo orientations for each cluster. Based on the electrostatic and geometric scoring functions, the algorithm then determines an optimized structure.

\section{Results and discussion}

\section{An. coluzzii SG transcriptome}

RNA-seq is a quite recent technology that allows obtaining the whole transcriptome and absolute gene expression measurements, for defined conditions. RNA-seq has been used previously to obtain a depth annotation of An. coluzzii midgut and, for different purposes, in other mosquitoes as An. funestus, An. albimanus and Ae. aegypti $[11,12,56-58]$.

For the characterization of An. coluzzii female SG transcriptome, we used RNA-seq to compare transcript abundance in P. berghei-infected and control uninfected SG. Three groups of 100 mosquitoes each, fed on infected and on uninfected healthy mice were used for RNA-seq analysis and further validation using qPCR. The oocysts counting on eighth day of infection showed that mosquitoes on infected group had $86-89 \%$ infection rate; groups showing lower infection rates were rejected.

The relative abundance of transcripts was analyzed. Of the total predicted transcriptome (15322 genes of An. coluzzii, according to version 72, ENSEMBL (http:// www.ensembl.org/index.html), 12690 genes and 13611 transcripts were found in the SG transcriptome. Of them, 2588 genes were differentially expressed in response to P. berghei infection (Additional file 4: Table S4), being 1578 (61 \%) upregulated and 1010 (39 \%) downregulated (Fig. 1a-c). RNA-seq data are available in the ArrayExpress database (www.ebi.ac.uk/arrayexpress) under accession number E-MTAB-3415. These results indicates that RNA-seq is a high-throughput technique enabling to detect a high number of transcripts when compared with other approaches $[59,60]$, as microarrays that was recently used by Waisberg and co-workers [61], finding 43 genes differentially expressed.

To increase insight into SG transcriptome of An. coluzzii adult female mosquitos, differentially expressed products were functionally annotated using Gene Ontology (GO) terms description (Functional Class, Biological Process and Molecular Function) (Additional file 4: Table S4; Fig. 1a, d). Most of the genes were assigned as unknown function due to the lack of functional data. Quantitatively, genes belonging to Metabolism, Replication-Transcription-Translation (RTT) and Transport classes showed to be the most upregulated (Fig. 1b), whereas Metabolism, Cell Function and Transport were the most downregulated classes (Fig. 1c).

The expression of 18 genes identified as differentially expressed by RNA-seq (10 upregulated and 8 downregulated in response to infection) was analyzed by qPCR and RNA-seq results confirmed in 15 of them (Additional file 1: Table S1). Regression analysis between the two methods revealed a strong correlation between mRNA levels estimated by RNA-seq and qPCR (Pearson's correlation coefficient $r=0.7957$ ) (Additional file 5: Figure S1). 


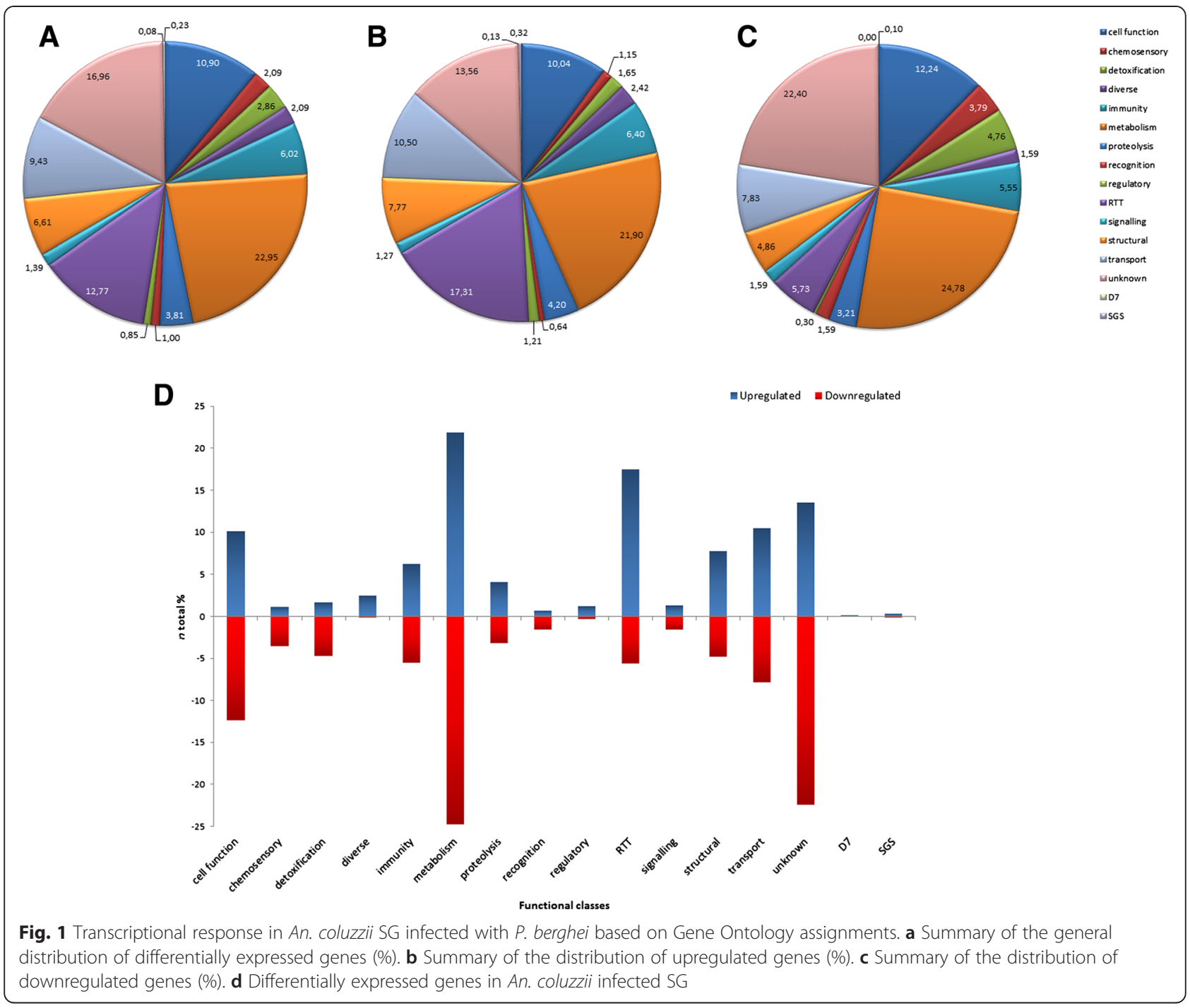

As the majority of genes had a low fold-change value (75.6\% between 1.00 and 1.24), a cut-off of 1.25 was used (Fig. 2a) to obtain a working list including only genes with high fold-change values. For this cut-off, a total of 605 genes were obtained (Additional file 4: Table S4). The g: Profiler (http://biit.cs.ut.ee/gprofiler/) public web server for characterizing and manipulating gene lists from highthroughput genomics, was employed to identify gene classes or categories more represented within our RNAseq data.

The molecular function "endopeptidase" was the category more statistically represented (P-value $<0.001$ ) (Additional file 6: Table S5). Genes presenting an "endopeptidase activity" were classified as belonging to the Immunity and Proteolysis classes, as they participate in different pathways related to both classes.

Based on both g: Profiler and RNA-seq data, the predicted and more represented functional classes (Immunity,
Proteolysis, Metabolism, RTT and Transport) were analyzed in detail.

\section{Immunity genes}

Transcriptomic analysis using the fold - change cut-off 1.25 showed the highest number of differentially expressed genes among the immunity functional class from which 49 were upregulated and 06 downregulated. Within immunity, the subcategories classified according functional sub-class as Clip-Domain Serine Proteases (26\%), PRR (Pattern recognition receptors) (16.7\%), melanization (14.8\%), LRR (leucine-rich repeat) (13\%), and Imd pathway (13\%) were the most highly upregulated (Fig. $2 b$ ).

In a previous report, $A n$. funestus transcriptome challenged with Plasmodium sp. was analyzed using BLAST to match results from RNA-seq and the An. coluzzii genome, showing TEP, LRIM1 and Clip-Domain Serine Proteases (SPCLIP1) among the highest upregulated 


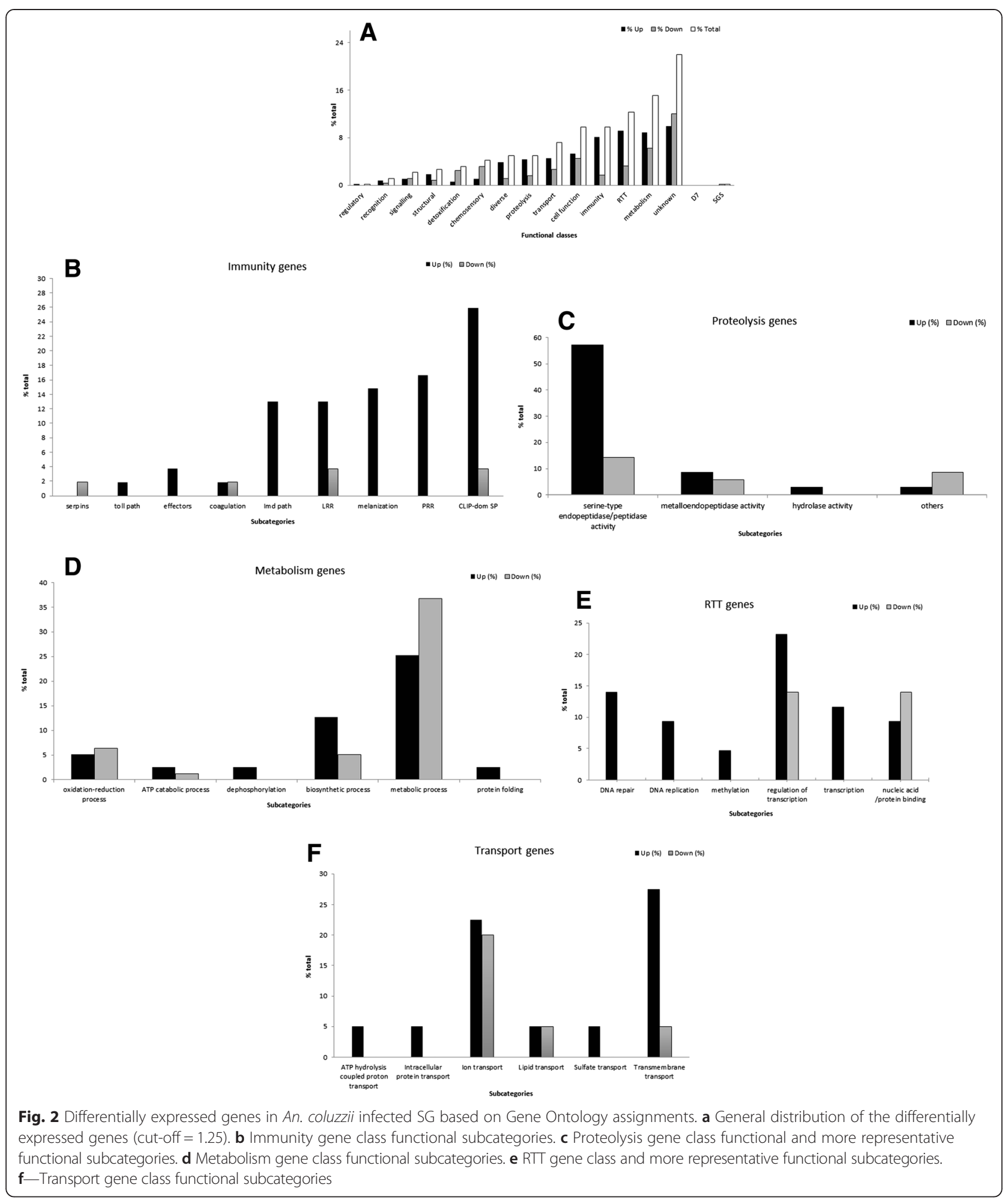

immunity genes [11]. SPCLIP1 regulates the accumulation of TEP1 on malaria parasites and bacteria and can lead to distinct defense reactions including lysis and melanization of the pathogen [62].
Our data also showed that seven $L R R$ genes were found upregulated; these proteins are related to the control of the complement-like protein TEP1 function having, as well, an important role on innate immune 
defense [63-65]. PRR are transcripts determinant for resistance to Plasmodium infection [66] and melanization, and also identified as playing an important role on antibacterial immune response on An. coluzzii [67]. Previous results highlighted the fact that the Imd pathway in An. coluzzii is part of an effort to limit the malaria transmission cycle, associating the Imd-directed immune response against $P$. falciparum [68] and showing that these genes are upregulated in response to Plasmodium infection [15]. Equivalent data were obtained in the present study, where all Imd-pathway genes (AGAP010815, AGAP007035, AGAP007036, AGAP006348, AGAP007033 and $A G A P 005693)$ were found to be upregulated. These findings support the evidence that Imd pathway and PRR genes play a part in mosquito response to Plasmodium infection.

The gene AGAP006421 was also found upregulated. It is considered a member of the antigen AG5 family of the SG mosquito transcripts [19], categorized as an immunity gene, but related with a family of secreted proteins with different functions [69].

\section{Proteolysis genes}

GO analysis revealed that genes encoded proteins potentially related to proteolysis were more upregulated in mosquitoes SG infected with $P$. berghei. Twenty-five genes were found to be upregulated while 10 were downregulated, being the majority under the molecular function categorized as serine-type endopeptidases (57.1 \%) (Fig. 2c).

The most upregulated transcript gene under this GO term was the AGAP002596, which corresponds to a metallopeptidase that have been associated with tissue invasion and infection by many pathogens [70].

It is known that this gene class is involved in blood meal and sugar digestion, namely in proteolytic events during blood-feeding on vertebrate hosts or in digestion of extracellular matrix components [71] and is, usually, upregulated in fed mosquito females [72]. Moreover, the biological significance of positive regulation may also be related with the role of these genes in immunity being part of the host defense system to limit spread of the parasite [73]. In addition, it have been showed that a salivary serine protease is related in Dengue transmission by Aedes mosquitoes [74].

\section{Metabolism genes}

We found that genes putatively involved in metabolism functional class were highly transcribed in mosquito SG (Fig. 2d) in agreement with a previous transcriptomic analysis of Ae. aegytpi SG infected with Dengue virus suggesting parasite infection level is linked to physiological processes modifications [75].

An insulin-like peptide precursor and one gene classified as related with oxidation-reduction process were the most upregulated, while genes belonging to protein phosphorylation and lipid metabolism were less expressed. Insulin-like peptides (ILPs) regulate several biological processes as metabolism and immunity to infection. Previous reports conducted in several mosquito species have shown that ILPs secretion and action may be responsive in Plasmodium-infected females and potentially alter metabolism and innate immunity [76]. Our data show that gene expression changes in response to infection indicates the upregulation of genes associated with ubiquitindependent protein catabolic processes and with amino acid metabolism. The enrichment of functional terms such as ubiquitin-dependent proteasome was also denoted for insects facing dehydration stress [77]. Among the transcripts encoding metabolism, two, involved in nitric oxide biosynthetic process, were found to be upregulated. Nitric oxide synthase expression and nitric oxide increases in $A n$. coluzzii and An. stephensi midgut after Plasmodium parasite infection $[78,79]$ limiting parasite development within the mosquito [80]. Further, within this GO term, transcripts linked to sugar metabolism were mostly upregulated whereas those associated with lipid metabolism were essentially downregulated, which may be connected to cell repair in response to infection and/or to the production of metabolites needed for sporozoites progress [59].

\section{RTT genes}

Translational regulation allows cells to respond to stimuli and modify protein levels. For most of the genes, is not known if an increase on translation is directly related to defence reactions against Plasmodium sp. infection, but some reports evidence that translational regulation of gene expression in mosquito midguts has a profound impact on the anti-malaria responses [81].

As many as 43 genes, 31 upregulated and 12 downregulated (Fig. 2e) were found to be transcribed in SG of An. coluzzii belonging to the RTT class, which includes the second highest number of genes differentially expressed in response to parasite infection (Fig. 2a). Transcript genes linked to the biological processes DNA replication and DNA repair were exclusively upregulated, probably acting as cell defense from infection. Our data is in accordance to the transcriptome profile of $A n$. coluzzii hemocytes upon $P$. berghei infection, also showing that the RTT class was also significantly upregulated [82]. RTT genes may regulate protein expression required for PlasmodiumSG interaction and thus, manipulated by the parasite to facilitate infection.

\section{Transport genes}

Several transport transcripts (28 upregulated and 12 downregulated) were identified in SG (Fig. 2f). Among the subcategories described, we found that transmembrane transport transcripts were the most represented (27.5\%). 
The most abundant and upregulated transcript (AGAP007752), encoding a protein referred as EAA12343, was submitted to a location predictor analysis, confirming its inclusion into this subcategory. Although evidences suggest that this gene is not SG-specific, being preferentially expressed in Malpighian tubules from male mosquitoes [72], both RNA-seq and qPCR experiments showed a high upregulation expression in SG female mosquitoes during Plasmodium infection. Moreover, the GO annotation predict the function of this transcript as glucose transporter and, supported by findings that carbohydrates transporters may have an important role on Plasmodium transmission [6-9], we selected the AGAP007752 gene for further analysis.

\section{Other functional classes}

Among the genes selected to be analyzed by qPCR, the HPX11 gene (AGAP010899), belonging to the detoxification functional class and, included in the biological process designated as response to oxidative stress, was one of the most highly downregulated (Additional file 1: Table S1). Transcription alteration of detoxification genes in response to bacteria and Plasmodium has been described [73]. It is possible that subexpression might be related with the presence of the parasite, as infection may induce stress response in mosquitoes [83], resulting in induced and or repressed genes [73]. During mosquito response to infection, active nitrogen and oxygen radicals are produced to contain Plasmodium infection [84]. These products may represent potential oxidative stress that can be enhanced or eliminated by detoxification enzymes.

Several genes with putative chemosensory molecular function as odorant binding proteins (OPB) were transcribed in An. coluzzii SG after infection. The expression of one of these genes, OBP20, was evaluated by RNAseq and qPCR, showing to be downregulated in both assays (Additional file 1: Table S1). Olfaction plays a vital role in guiding mosquito behaviours and contributing to their ability to transmit pathogens but response mediated by chemosensory genes may vary according to the pathogen [73, 85].

In addition, two members of the D7 family, AGAP008278 and AGAP008279 (D7 long form L1 and L2, respectively) were found upregulated in SG. It is suggested that D7 SG proteins are distantly related with OBP, inhibiting hemostasis during hematophagy and therefore, facilitating blood feeding [86].

Six genes that codify five members of the salivary gland surface (SGS) were differentially expressed (AGAP000548 (SGS1b), AGAP000150 (SGS6), AGAP008215 and AGAP008216 (SGS7), AGAP010647 (SGS8) and AGAP003841 (SGS10)). These transcripts codify a family of immunogenic mosquito SG proteins involved during blood feeding and also parasite infection $[87,88]$.

\section{AGAP007752 silencing experiments}

Considering that membrane transporter proteins of Anopheles sp. SG have an important role on Plasmodium transmission, we select the AGAP007752 SG gene coding to a membrane transport protein to perform RNAi-mediated gene silencing. This gene showed to be the most upregulated within the transport functional class regarding RNA-seq analysis (Additional file 4: Table S4), showing to be as well upregulated in qPCR experiments (Additional file 1: Table S1).

The AGAP007752 gene was annotated as predicted coding for a protein with transmembrane transporter activity (according to Gene Ontology annotation: http://www.ebi. ac.uk/QuickGO/GTerm?id=GO:0055085). Protein-protein interaction prediction analysis using the platform STRING (string-db.org) showed that this target interacts with only four proteins (AGAP000128, AGAP000220, AGAP003039 and AGAP006360). Two of them, AGPA006360 and AGAP000220 were found on RNA-seq results but they showed no similarity function. The low number of interactions and no similar function associated suggests this target as a good candidate for further analysis. Thus, to characterize the function of this gene in Plasmodium sporozoite SG invasion, putative function analysis and RNA interference (RNAi)-mediated gene knockdown was carried out in infected and uninfected mosquitoes.

Performing three independent RNAi assays, we found a significant $99 \%, 82 \%$ and $89 \%(146.7+9.6)$ (unpaired two-tailed $t$-test, $P<0.01)$ reduction on endogenous mRNA levels (Fig. 3a). AGAP007752 knockdown significantly reduced the number of sporozoites present in the SG 18 days post-infection by $45 \%, 43 \%$ and $44 \%(9.9+5.1)$ (unpaired two-tailed $t$-test, $P<0.01$ ) when compared to controls (Fig. 3b).

Glucose transporters are a wide group of membrane proteins essential for transport and metabolism of glucose in cells of diverse organisms from microbes to humans [89]. The EAA12343 was categorized as glucose transporter and, as other proteins from this family, is likely to be glycosylated [90]. Previous reports have suggests that Plasmodium spp. propagation in mosquitoes consumes vector nutrients [8] and specific glycosylated proteins might function as parasite receptors on the basal lamina, of the distal lateral and the medial lobes of the SG $[6,91]$. Furthermore, the invasion of $P$. gallinaceum sporozoites into the SG of Aedes aegypti is blocked by a carbohydrate binding protein or lectin [7], confirming the role of glycosylated proteins as receptors for malaria sporozoite-SG interaction.

In accordance to our data, it was shown that the knockdown of the sugar transporter trehalose (AgTreT1) significantly reduced parasite oocysts in the midguts of An. gambiae infected with P. falciparum; threalose is the predominant sugar in mosquito hemolymph decreasing 


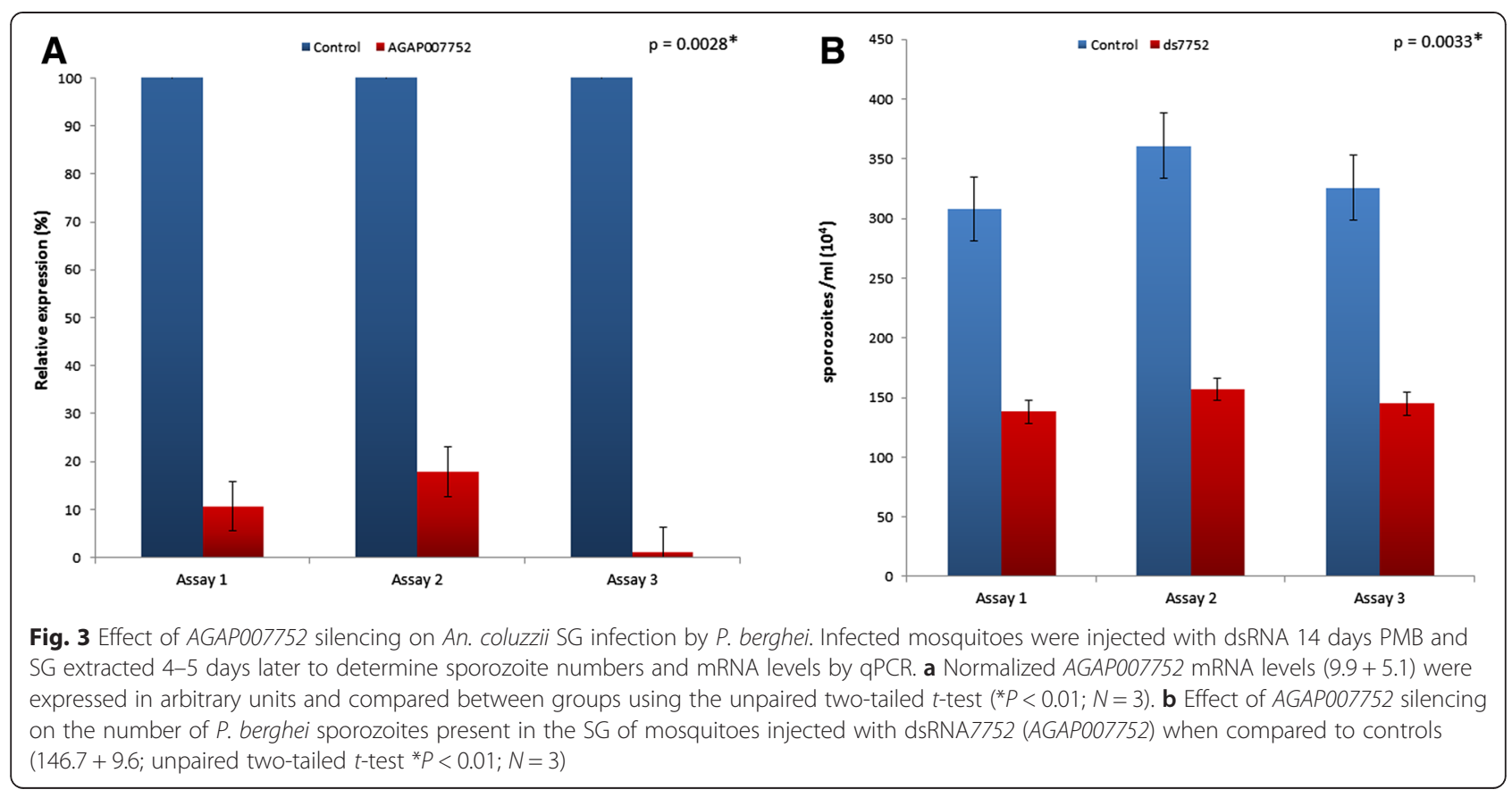

after Plasmodium infection [8]. AgTreT1 showed to be critical to maintain hemolymph trehalose concentration and a positive mediator for parasite growth and propagation during the oocyst stage. Sporozoite may scavenger and metabolizes trehalose directly or trehalose may be hydrolyzed to glucose by either the vector or the sporozoite [8]. Rosinski-Chupin and co-workers [59] found several genes involved in energy and glucose metabolism upregulated in SG infected by Plasmodium sp., assuming that this alterations may be favorable for the sporozoite maturation and/or transmission to the vertebrate host. According with these findings, it is likely that the EAA12343 protein might act as a sporozoite receptor for entry in the SG and/or have part on the maintenance of parasite optimal conditions, as glucose level, supplying energy for the vertebrate infection.

Other proteins have been described as related to Plasmodium infection on Anopheles spp.. For instance, it have been demonstrate that Saglin (a protein found in Anopheles SG) and their interaction with TRAP (a surface protein present in Plasmodium parasites) is essential for parasite invasion in SG [2]. Another protein, AgESP, was found in both midgut and SG and described as having an important role on Plasmodium infection, reducing midgut invasion and the number of sporozoites, after silencing. Some proteins, however, show a protective effect on Plasmodium infection. This is the case of the SRPN6, a marker of Plasmodium infection in An. coluzzii SG, as once the gene is silenced, the number of sporozoites increases in SG [25]. Further, the passage through the SG is necessary for sporozoite capacity, as the complete acquisition of gliding locomotion and cell traversal [92].

\section{An. coluzzii protein putative function}

Classifying the putative function of the An. coluzzii protein coded by the AGAP007752 gene as a sugar transporter was done by performing five PSI-BLAST [93] interactions using the default settings-a pfam database search [94] confirmed this classification. The top hits were from insect trehalose and glucose transporters ( $E$ value 3e-38). It was previously shown that insects glucose transporters cluster with several organisms, including mammalian glucose transporters and not with insecta trehalose transporters. suggesting a function related to phylogenetic clustering [95]. Maximum likelihood and Bayesian phylogenetic analyses with threalose and glucose transporters from members of metazoa (Mammalia, Insecta and Trematoda) show that $A n$. coluzzii AGAP007752 protein (named as EAA12343) (Fig. 4, red star) cluster together with glucose transporters from the three metazoan clades (Fig. 4, blue box) and not with the trehalose transporters from insecta (Fig. 4, green box) (Additional file 7: Figure S2, Additional file 8: Figure S3 and Additional file 9: File S1), in agreement with previous findings [95]. The GLUT/SLC2A glucose transporter family in humans has been categorized into three classes: class 1 comprises GLUT1 to GLUT4 and GLUT14-L; class 2 comprises GLUT5, GLUT7, GLUT9, and GLUT11 and class 3 comprises GLUT6, GLUT8, GLUT10 and GLUT12 [96-98]. We found that EAA12343 cluster together with an insecta glucose transporter (NIST1) that was previously characterized [99] and both of them cluster together with class III human glucose transporters (Fig. 4, blue box). 


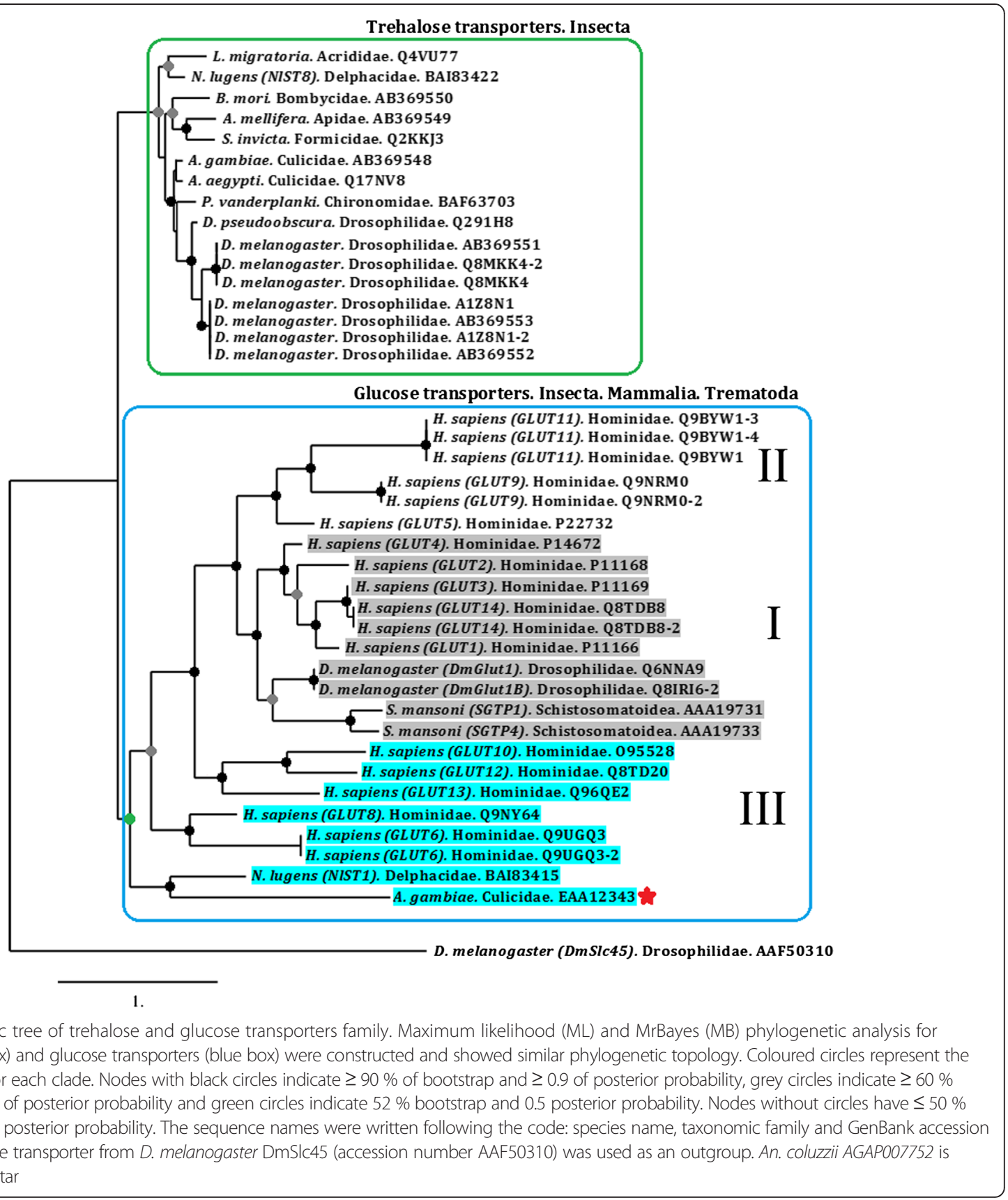

To confirm our phylogenetic classification, we performed a multiple amino acid sequence alignment of glucose transporters class III (NIST1GLUT/GLUT8/ GLUT6/GLUT10/GLUT12). The alignment shows that the An. coluzzii glucose transporter identified in this study share important functional domains with other members of this class of glucose transporters (Fig. 5). For example, a common structural feature of the GLUT/ SLC2 family members is the presence of 12 transmembrane domains (TM) and a unique N-linked oligosaccharide side-chain present in a large extracellular loop either to the $\mathrm{N}$-terminus (classes I and II) or to the Cterminus of the protein (class III) (Fig. 5, red boxes). The conserved glycine (G) residues in the transmembrane domains "(TM) 1, 4, 5, 7, 8, and 10" among class III glucose transporters (Fig. 5, blue boxes) are thought to be critical in stabilizing the structure of GLUT/ SLC2A [96]. Another difference among glucose transporter classes is the proline-containing motif between TM6 and TM7. Classes I and II possess residues PETPR/ PESPR, respectively [95], while class III possess "PXXPR" [95] (Fig. 5, asterisks above black box). Finally, the 


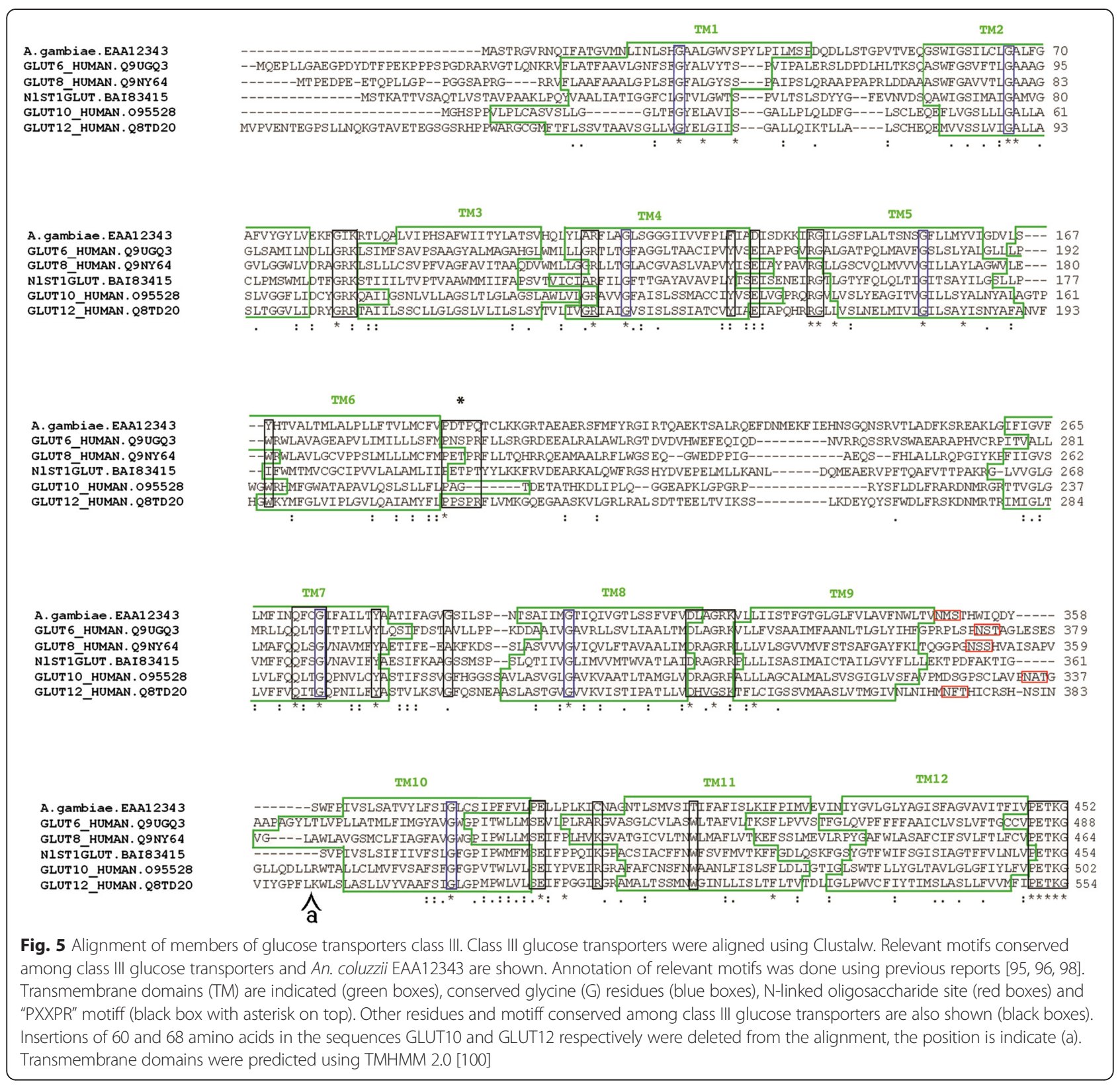

presence of a dileucine motif in the amino-terminal tail of some members of class III glucose transporters has been previosuly reported [96]. In our case, even when leucines residues were found in the amino-terminus of both NIST1 and EAA12343, no dileucine motif was present.

The predicted tertiary structure of EAA12343 is depicted in Fig. 6a and clearly shows the 12 TM domains common among membrane bound transporters (as indicated by the alignment in Fig. 5). There are several GLUT/SLC2A crystal structures available, however, not all classes have been resolved. Regardless of the different classes, the overall structure GLUT/SLC2A is highly conserved. In Fig. 6b we demonstrate the conservative nature of the structural backbone of EAA12343 compared with two other sugar transporters for which crystal structures are available. The overall root mean square deviation of the superimposed structures in Fig. $6 \mathrm{~b}$ is $<3.5 \AA$, indicating that the tertiary model of EAA12343 is adequate for further computational analyses.

\section{Conclusions}

This is the first transcriptome analysis of An. coluzzii SG infected with $P$. berghei by RNA-seq, producing a catalogue of SG genes differentially expressed in response to infection. Among the differentially expressed genes, the sugar transporter AGAP007752 gene was the most upregulated after $P$. berghei infection and the RNAi-mediated 


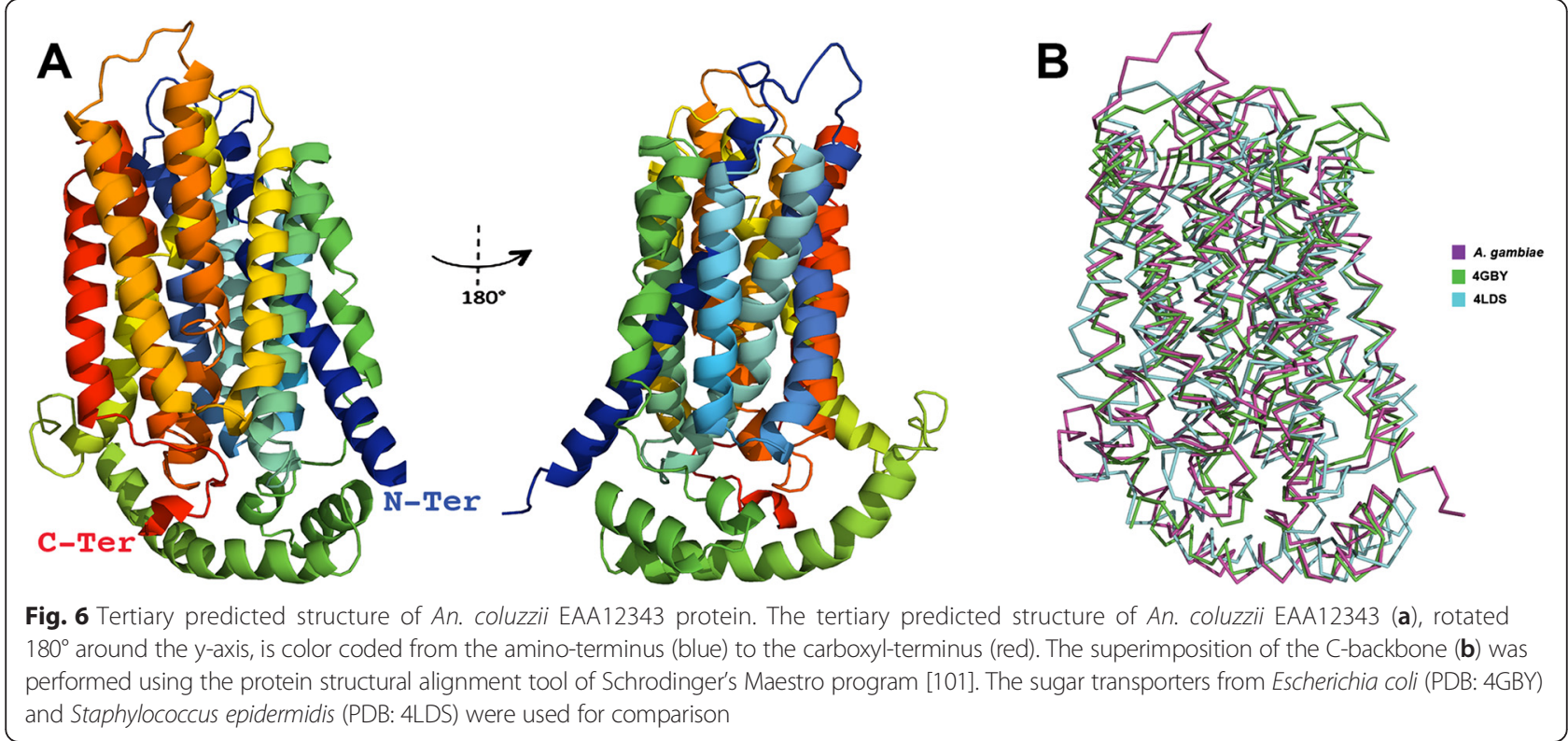

gene knockdown data suggests that AGAPO07752 encoded a protein that may be important to malaria transmission. Thus, we suggest that this protein may have an analogous role to other sugar transporters as a sporozoite receptor and/or in the maintenance of the optimal conditions for parasite egress from salivary glands.

Further analyses are being conducted to go deeper into the role of EAA12343 protein on P. berghei transmission, as protein location in SG and its impact on mosquito physiology after gene-silencing.

Our set of results provide a valuable resource for future studies in this crucial malaria vector. The improvement on the understanding of salivary gland gene expression and function will contribute for the progress on malaria control actions.

\section{Additional files}

Additional file 1: Table S1. mRNA levels for selected genes as obtained by RNA-seq and qPCR. (DOCX $24 \mathrm{~kb}$ )

Additional file 2: Table S2. List of primers used for $\mathrm{qPCR}$ gene expression confirmation. (DOCX $27 \mathrm{~kb})$

Additional file 3: Table S3. List of primers used for double stranded RNA synthesis. (DOCX $17 \mathrm{~kb}$ )

Additional file 4: Table S4. List of genes expressed in the female salivary glands of An. coluzzii of the group infected with P. berghei vs. uninfected. The excel file has two sheets: Sheet 1 list the genes that are expressed using one standard deviations above or below the average fold change across all genes. Sheet 2 lists the genes that are expressed using cut-off 1.25. The gene list is further sorted into different functional groups, according to the predicted function of the genes. Functional sub-classes, Biological process and Molecular Functional information were obtained according to Gene Ontology annotation, Ensembl metazoa (metazoa.ensembl.org) and Uniprot (uniprot.org). (XLSX 338 kb)
Additional file 5: Figure S1. Comparison of mRNA levels determined by RNA-seq and gPCR. The ratios of mRNA levels found in RNA-seq were compared with the corresponding values obtained using $\mathrm{QPCR}$. A strong correlation was observed between the two data sets as demonstrated by the Pearson's correlation coefficient $(P=0.7957)$. (TIFF $8 \mathrm{~kb}$ )

Additional file 6: Table S5. Results from g: Profiler analysis. (XLS $97 \mathrm{~kb}$ ) Additional file 7: Figure S2. MrBayes phylogenetic tree of trehalose and glucose transporters family. Maximum likelihood (ML) phylogenetic analysis for trehalose and glucose transporters. Bootstraps values are shown. (PDF $17 \mathrm{~kb}$ )

Additional file 8: Figure S3. Maximum likelihood phylogenetic tree of trehalose and glucose transporters family. Maximum likelihood (ML) phylogenetic analysis for trehalose and glucose transporters. Bootstraps values are shown. (PDF $5 \mathrm{~kb}$ )

Additional file 9: File S1. Alignment for trehalose and glucose transporters used in the phylogenetic analysis. (DOC $113 \mathrm{~kb}$ )

\section{Competing interests}

The authors declare that they have no competing interests.

\section{Authors' contributions}

$J F$, VR and AD designed the study. RP-S performed the mosquito experiments. $J F, R P-S, L P C, L B$ and AD performed data analysis. AC-C and JJV performed phylogenetic analysis. RP-S, JF and AD wrote the manuscript. All authors edited and approved the final manuscript.

\section{Acknowledgements}

We are grateful to Dr. Dinora Lopes for technical support and valuable suggestions for the sporozoite quantification. We thank Ana Catarina Alves for assistance with mosquito rearing and Mário da Costa for his support on mosquito dissection. This work was partially supported by the GHTM-UID/Multi/04413/2013 project and by the PhD course on Biomedical Sciences, IHMT-UNL.

\section{Author details}

${ }^{1}$ Instituto de Higiene e Medicina Tropical (IHMT), Lisbon, Portugal. ${ }^{2}$ Unidade de Biofísica e Expressão Genética, Instituto de Medicina Molecular (IMM), Lisbon, Portugal. ${ }^{3}$ Center for Infection and Immunity of Lille (CIIL), Institut Pasteur de Lille, Lille, France. ${ }^{4} \mathrm{SaBio}$. Instituto de Investigación de Recursos Cinegéticos, IREC-CSIC-UCLM-JCCM, Ciudad Real, Spain. Institute of Parasitology, Biology Centre of the Academy of Sciences of the Czech 
Republic, České Budějovice, Czech Republic. ${ }^{6}$ Department of Veterinary Pathobiology, Center for Veterinary Health Sciences, Oklahoma State University, Stillwater, USA. ${ }^{7}$ Global Health and Tropical Medicine (GHMT), Instituto de Higiene e Medicina Tropical (IHMT), Lisbon, Portugal.

Received: 2 July 2015 Accepted: 9 September 2015 Published online: 23 September 2015

\section{References}

1. WHO (World Health Organization). Fact sheet No94 Updated December 2013 http://www.who.int/malaria/publications/world_malaria_report_2013/en/ Acessed 10 Ago 2015

2. Ghosh AK, Devenport M, Jethwaney D, Kalume DE, Pandey A, Vernon E, et al. Malaria Parasite Invasion of the Mosquito Salivary Gland Requires Interaction between the Plasmodium TRAP and the Anopheles Saglin Proteins. PloS Pathog. 2009;(1):e1000265.

3. Kappe SH, Gardner MJ, Brown SM, Ross J, Matuschewski K, Ribeiro JM, et al Exploring the transcriptome of the malaria sporozoite stage. Proc Natl Acad Sci U S A. 2001;98:9895-900.

4. Mueller A-K, Kohlhepp F, Hammerschmidt C, Michel K. Invasion of mosquito salivary glands by malaria parasites: Prerequisites and defense strategies. Int J Parasitol. 2011:40:1229-35.

5. Brennan JD, Kent M, Dhar R, Fujioka H, Kumar N. Anopheles gambiae salivary gland proteins as putative targets for blocking transmission of malaria parasites. Proc Natl Acad Sci U S A. 2000;97:13859-64.

6. Dinglasan RR, Valenzuela JG, Azad AF. Sugar epitopes as potential universa disease transmission blocking targets. Insect Biochem Mol Biol. 2005;35:1-10.

7. Zieler H, Nawrocki JP, Shahabuddin M. Plasmodium gallinaceum ookinetes adhere specifically to the midgut epithelium of Aedes aegypti by interaction with a carbohydrate ligand. J Exp Biol. 1999;202(Pt 5):485-95.

8. Liu K, Dong Y, Huang Y, Rasgon JL, Agre P. Impact of trehalose transporter knockdown on Anopheles gambiae stress adaptation and susceptibility to Plasmodium falciparum infection. Proc Natl Acad Sci U S A. 2013;110:17504-9.

9. Basseri HR, Doosti S, Akbarzadeh K, Nateghpour M, Whitten MM, Ladoni H. Competency of Anopheles stephensi mysorensis strain for Plasmodium vivax and the role of inhibitory carbohydrates to block its sporogonic cycle. Malar J. 2008;7:131

10. Wilhelm BT, Landry J-R. RNA-Seq-quantitative measurement of expression through massively parallel RNA-sequencing. Methods. 2009;48:249-57.

11. Crawford JE, Guelbeogo WM, Sanou A, Traoré A, Vernick KD, Sagnon N, et al. De novo transcriptome sequencing in Anopheles funestus using Illumina RNA-seq technology. PLoS One. 2010;5:e14202.

12. Bonizzoni M, Afrane $Y$, Dunn WA, Atieli FK, Zhou G, Zhong D, et al. Comparative transcriptome analyses of deltamethrin-resistant and -susceptible Anopheles gambiae mosquitoes from Kenya by RNA-Seq. PLoS One. 2012;7:e44607.

13. Antunes S, Galindo RC, Almazán C, Rudenko N, Golovchenko M, Grubhoffer $L$, et al. Functional genomics studies of Rhipicephalus (Boophilus) annulatus ticks in response to infection with the cattle protozoan parasite, Babesia bigemina. Int J Parasitol. 2012;42:187-95.

14. Deng Y, Wang CC, Choy KW, Du Q, Chen J, Wang Q, Li L, Chung TK, Tang T. Therapeutic potentials of gene silencing by RNA interference: Principles, challenges, and new strategies. Gene. 2014;217-27.

15. Blandin S, Shiao S-H, Moita LF, Janse CJ, Waters AP, Kafatos FC, et al. Complement-like protein TEP1 is a determinant of vectorial capacity in the malaria vector Anopheles gambiae. Cell. 2004;116:661-70.

16. Osta MA, Christophides GK, Kafatos FC. Effects of mosquito genes on Plasmodium development. Science. 2004;303:2030-2.

17. Holt RA, Subramanian GM, Halpern A, Sutton GG, Charlab R, Nusskern DR, et al. The genome sequence of the malaria mosquito Anopheles gambiae. Science. 2002;298:129-49.

18. Nene $V$ et al. Europe PMC Funders Group Genome sequence of Aedes aegypti, a major arbovirus vector. Science. 2007;316:1718-23.

19. Arcà B, Lombardo F, Valenzuela JG, Francischetti IMB, Marinotti O, Coluzzi M, et al. An updated catalogue of salivary gland transcripts in the adult female mosquito, Anopheles gambiae. J Exp Biol. 2005;208(Pt 20):3971-86.

20. Calvo E, Dao A, Phan V, Ribeiro J. An insight into the sialome of Anopheles funestus reveals an emerging pattern in anopheline salivary protein families. Insect Biochem Mol Biol. 2007:37:164-75.

21. Calvo E, Andersen J, Franscischetti A, de Capurro M, DeBianchi A, James A, et al. The transcriptome of adult female Anopheles darlingi salivary glands. Insect Mol Biol. 2004;13:73-88.
22. Ribeiro JMC. A catalogue of Anopheles gambiae transcripts significantly more or less expressed following a blood meal. Insect Biochem Mol Biol. 2003;33:865-82.

23. Valenzuela JG, Francischetti IMB, Pham VM, Garfield MK, Ribeiro JMC Exploring the salivary gland transcriptome and proteome of the Anopheles stephensi mosquito. Insect Biochem Mol Biol. 2003:33:717-32.

24. Fontaine A, Fusaï T, Briolant S, Buffet S, Villard C, Baudelet E, et al. Anopheles salivary gland proteomes from major malaria vectors. BMC Genomics. 2012;13:614.

25. Pinto SB, Kafatos FC, Michel K. The parasite invasion marker SRPN6 reduces sporozoite numbers in salivary glands of Anopheles gambiae. Cell Microbiol. 2008;10:891-8

26. Chertemps T, Mitri C, Perrot S, Sautereau J, Jacques J-C, Thiery I, et al. Anopheles gambiae PRS1 modulates Plasmodium development at both midgut and salivary gland steps. PLoS One. 2010;5:e11538.

27. Rodrigues J, Oliveira GA, Kotsyfakis M, Dixit R, Molina-Cruz A, Jochim R, et al. An epithelial serine protease, AgESP, is required for Plasmodium invasion in the mosquito Anopheles gambiae. PLoS One. 2012;7:e35210.

28. Sokhna C, Ndiath $\mathrm{MO}$, Rogier $\mathrm{C}$. The changes in mosquito vector behaviour and the emerging resistance to insecticides will challenge the decline of malaria. Clin Microbiol Infect. 2013:19:902-7.

29. Moreno-Cid JA, Pérez de la Lastra JM, Villar M, Jiménez M, Pinal R, EstradaPeña A, et al. Control of multiple arthropod vector infestations with subolesin/akirin vaccines. Vaccine. 2013;31:1187-96.

30. De la Fuente J, Moreno-Cid JA, Galindo RC, Almazan C, Kocan KM, Merino $\mathrm{O}$, et al. Subolesin/Akirin vaccines for the control of arthropod vectors and vectorborne pathogens. Transbound Emerg Dis. 2013;60 Suppl 2:172-8.

31. Armada A, Gazarini ML, Gonçalves LM, Antunes S, Custódio A, Rodrigues A et al. Generation of an antibody that recognizes Plasmodium chabaudi cysteine protease (chabaupain-1) in both sexual and asexual parasite life cycle and evaluation of chabaupain-1 vaccine potential. Exp Parasitol. 2013:135:166-74.

32. Canales M, Ballesteros C, Moreno-Cid JA, Espinosa AM, Villar M, de la Fuente J. Extractive bioconversion to produce the Aedes albopictus akirin in an aqueous two-phase system supporting Pichia pastoris growth and protein secretion. Biochem Eng J. 2009:46:105-14.

33. De la Fuente J, Moreno-Cid JA, Canales M, Villar M, de la Lastra JMP, Kocan KM, et al. Targeting arthropod subolesin/akirin for the development of a universal vaccine for control of vector infestations and pathogen transmission. Vet Parasitol. 2011;181:17-22

34. Janse C, Franke-Fayard B, Mair G, Ramesar J, Thiel C, Engelmann S, et al. High efficiency transfection of Plasmodium berghei facilitates novel selection procedures. Mol Biochem Parasitol. 2006:145:60-70.

35. Ayllón N, Villar M, Galindo RC, Kocan KM, Šíma R, López JA, et al. Systems Biology of Tissue-Specific Response to Anaplasma phagocytophilum Reveals Differentiated Apoptosis in the Tick Vector Ixodes scapularis. PLOS Genet 2015:11:e1005120.

36. Mortazavi A, Williams BA, McCue K, Schaeffer L, Wold B. Mapping and quantifying mammalian transcriptomes by RNA-Seq. Nat Methods. 2008:5:621-8.

37. Lee J, Ji Y, Liang S, Cai G, Müller P. On differential gene expression using RNA-Seq data. Cancer Inform. 2011;10:205-15.

38. Horton P, Park K-J, Obayashi T, Fujita N, Harada H, Adams-Collier CJ, et al WoLF PSORT: protein localization predictor. Nucleic Acids Res. 2007;35(Web Server issue):W585-7.

39. Blum T, Briesemeister S, Kohlbacher O. MultiLoc2: integrating phylogeny and Gene Ontology terms improves subcellular protein localization prediction. BMC Bioinformatics. 2009:10:274

40. Livak KJ, Schmittgen TD. Analysis of relative gene expression data using real-time quantitative PCR and the 2(-Delta Delta C(T)) Method. Methods. 2001;25:402-8

41. Edgar RC. MUSCLE: multiple sequence alignment with high accuracy and high throughput. Nucleic Acids Res. 2004;32:1792-7.

42. Castresana J. Selection of conserved blocks from multiple alignments for their use in phylogenetic analysis. Mol Biol Evol. 2000;17:540-52.

43. Anisimova M, Gascuel O. Approximate likelihood-ratio test for branches: A fast, accurate, and powerful alternative. Syst Biol. 2006;55:539-52.

44. Guindon S, Gascuel O. A Simple, Fast, and Accurate Algorithm to Estimate Large Phylogenies by Maximum Likelihood. Syst Biol. 2003;52:696-704.

45. Chevenet F, Brun C, Bañuls A-L, Jacq B, Christen R. TreeDyn: towards dynamic graphics and annotations for analyses of trees. BMC Bioinformatics. 2006;7:439. 
46. Cheng J, Baldi P. A machine learning information retrieval approach to protein fold recognition. Bioinformatics. 2006;22:1456-63.

47. Zhang Y. I-TASSER server for protein 3D structure prediction. BMC Bioinformatics. 2008:9:40

48. Vallat BK, Pillardy J, Májek P, Meller J, Cao B, Elber R. Building and assessing atomic models of proteins from structural templates: Learning and benchmarks. Proteins. 2010;76:930-45.

49. Raman S, Vernon R, Thompson J, Tyka M, Pei J, Kim D, et al. Structure prediction for CASP8 with all-atom refinement using Rosetta. Proteins. 2009;77:89-99.

50. Kelley LA, Sternberg MJE. Protein structure prediction on the Web: a case study using the Phyre server. Nat Protoc. 2009;4:363-71.

51. Arnold K, Bordoli L, Kopp J, Schwede T. The SWISS-MODEL workspace: a web-based environment for protein structure homology modelling. Bioinformatics. 2006;22:195-201.

52. Berjanskii M, Zhou J, Liang Y, Lin G, Wishart DS. Resolution-by-proxy: a simple measure for assessing and comparing the overall quality of NMR protein structures. J Biomol NMR. 2012;53:167-80.

53. Benkert $P$, Künzli M, Schwede T. QMEAN server for protein model quality estimation. Nucleic Acids Res. 2009;37(Web Server issue):W510-4.

54. McGuffin LJ, Buenavista MT, Roche DB. The ModFOLD4 server for the quality assessment of 3D protein models. Nucleic Acids Res. 2013;41(Web Server issue):W368-72.

55. Li X, Jacobson MP, Zhu K, Zhao S, Friesner RA. Assignment of Polar States for Protein Amino Acid Residues Using an Interaction Cluster Decomposition Algorithm and its Application to High Resolution Protein Structure Modeling. Proteins Struct Funct Bioinforma. 2007:837(December 2006):824-37.

56. Padrón A, Molina-Cruz A, Quinones M, Ribeiro JMC, Ramphul U, Rodrigues J, et al. In depth annotation of the Anopheles gambiae mosquito midgut transcriptome. BMC Genomics. 2014;15:636.

57. Martínez-Barnetche J, Gómez-Barreto RE, Ovilla-Muñoz M, Téllez-Sosa J, García López DE, Dinglasan RR, et al. Transcriptome of the adult female malaria mosquito vector Anopheles albimanus. BMC Genomics. 2012;13:207.

58. Akbari OS, Antoshechkin I, Amrhein H, Williams B, Diloreto R, Sandler J, et al. The developmental transcriptome of the mosquito Aedes aegypti, an invasive species and major arbovirus vector. G3 (Bethesda). 2013;3:1493-509.

59. Rosinski-Chupin I, Briolay J, Brouilly P, Perrot S, Gomez SM, Chertemps T, et al. SAGE analysis of mosquito salivary gland transcriptomes during Plasmodium invasion. Cell Microbiol. 2007;9:708-24.

60. Dixit R, Sharma A, Mourya DT, Kamaraju R, Patole MS, Shouche YS. Salivary gland transcriptome analysis during Plasmodium infection in malaria vector Anopheles stephensi. Int J Infect Dis. 2009;13:636-46.

61. Waisberg M, Molina-Cruz A, Mizurini DM, Gera N, Sousa BC, Ma D, et al. Plasmodium falciparum Infection Induces Expression of a Mosquito Salivary Protein (Agaphelin) That Targets Neutrophil Function and Inhibits Thrombosis without Impairing Hemostasis. PLoS Pathog. 2014;10:e1004338.

62. Povelones M, Bhagavatula L, Yassine H, Tan LA, Upton LM, Osta MA, et al. The CLIP-domain serine protease homolog SPCLIP1 regulates complement recruitment to microbial surfaces in the malaria mosquito Anopheles gambiae. PLoS Pathog. 2013;9:e1003623.

63. Baxter RHG, Steinert S, Chelliah Y, Volohonsky G, Levashina EA, Deisenhofer J. A heterodimeric complex of the LRR proteins LRIM1 and APL1C regulates complement-like immunity in Anopheles gambiae. Proc Natl Acad Sci U S A. 2010;107:16817-22.

64. Povelones M, Upton LM, Sala KA, Christophides GK. Structure-function analysis of the Anopheles gambiae LRIM1/APL1C complex and its interaction with complement C3-like protein TEP1. PLoS Pathog. 2011;7:e1002023

65. Le BV, Williams M, Logarajah S, Baxter RHG. Molecular basis for genetic resistance of Anopheles gambiae to Plasmodium: structural analysis of TEP1 susceptible and resistant alleles. PLoS Pathog. 2012:8:e1002958.

66. Dong Y, Taylor HE, Dimopoulos G. AgDscam, a hypervariable immunoglobulin domain-containing receptor of the Anopheles gambiae innate immune system. PLoS Biol. 2006:4:e229

67. Lambrechts L, Vulule JM, Koella JC. Genetic correlation between melanization and antibacterial immune responses in a natural population of the malaria vector Anopheles gambiae. Evolution. 2004:58:2377-81.

68. Garver LS, Bahia AC, Das S, Souza-Neto JA, Shiao J, Dong Y, et al. Anopheles Imd Pathway Factors and Effectors in Infection Intensity-Dependent Anti-Plasmodium Action. PloS Pathog. 2012;8:7-9.

69. Yamazaki Y, Morita T. Structure and function of snake venom cysteine-rich secretory proteins. Toxicon. 2004;44:227-31.
70. Goulielmaki E, Siden-Kiamos I, Loukeris T. Functional characterization of Anopheles matrix metalloprotease 1 reveals its agonistic role during sporogonic development of malaria parasites. Infect Immun. 2014;82:4865-77.

71. Das S, Radtke A, Choi Y-J, Mendes AM, Valenzuela JG, Dimopoulos G. Transcriptomic and functional analysis of the Anopheles gambiae salivary gland in relation to blood feeding. BMC Genomics. 2010;11:566.

72. Baker DA, Nolan T, Fischer B, Pinder A, Crisanti A, Russell S. A comprehensive gene expression atlas of sex-and tissue-specificity in the malaria vector, Anopheles gambiae. BMC Genomics. 2011;12:1-12.

73. Aguilar R, Jedlicka AE, Mintz M, Mahairaki V, Scott AL, Dimopoulos G. Global gene expression analysis of Anopheles gambiae responses to microbial challenge. Insect Biochem Mol Biol. 2005;35:709-19.

74. Conway MJ, Watson AM, Colpitts TM, Dragovic SM, Li Z, Wang P, et al. Mosquito saliva serine protease enhances dissemination of dengue virus into the mammalian host. J Virol. 2014;88:164-75.

75. Sim S, Ramirez JL, Dimopoulos G. Dengue virus infection of the Aedes aegypti salivary gland and chemosensory apparatus induces genes that modulate infection and blood-feeding behavior. PLoS Pathog. 2012;8:e1002631.

76. Marquez AG, Pietri JE, Smithers HM, Nuss A, Antonova Y, Drexler AL, et al. Insulin-like peptides in the mosquito Anopheles stephensi: Identification and expression in response to diet and infection with Plasmodium falciparum. Gen Comp Endocrinol. 2011;173:303-12.

77. Teets NM, Peyton JT, Colinet H, Renault D, Kelley JL, Kawarasaki $Y$, et al. Gene expression changes governing extreme dehydration tolerance in an Antarctic insect. Proc Natl Acad Sci U S A. 2012;109:20744-9.

78. Luckhart S, Vodovotz Y, Cui L, Rosenberg R. The mosquito Anopheles stephensi limits malaria parasite development with inducible synthesis of nitric oxide. Proc Natl Acad Sci U S A. 1998:95:5700-5.

79. Peterson TML, Gow AJ, Luckhart S. Malaria Parasite Infection. Free Radic Biol Med. 2007:42:132-42

80. Lim J, Gowda DC, Luckhart S, Krishnegowda G. Induction of nitric oxide synthase in Anopheles stephensi by Plasmodium falciparum: mechanism of signaling and the role of parasite Glycosylphosphatidylinositols Induction of Nitric Oxide Synthase in Anopheles stephensi by Plasmodium falciparum : Mechanis. Infect Immun. 2005;73:2778-89.

81. Mead EA, Li M, Tu Z, Zhu J. Translational regulation of Anopheles gambiae mRNAs in the midgut during Plasmodium falciparum infection. BMC Genomics. 2012:13:366.

82. Baton LA, Robertson A, Warr E, Strand MR, Dimopoulos G. Genome-wide transcriptomic profiling of Anopheles gambiae hemocytes reveals pathogen-specific signatures upon bacterial challenge and Plasmodium berghei infection. BMC Genomics. 2009:10:257.

83. Dimopoulos G, Christophides GK, Meister S, Schultz J, White KP, Barillas-Mury C, et al. Genome expression analysis of Anopheles gambiae: responses to injury, bacterial challenge, and malaria infection. Proc Natl Acad Sci U S A. 2002;99:8814-9.

84. Kumar S, Christophides GK, Cantera R, Charles B, Han YS, Meister S, et al. The role of reactive oxygen species on Plasmodium melanotic encapsulation in Anopheles gambiae. Proc Natl Acad Sci U S A. 2003;100:14139-44.

85. Deng Y, Yan H, Gu J, Xu J, Wu K, Tu Z, et al. Molecular and Functional Characterization of Odorant-Binding Protein Genes in an Invasive Vector Mosquito, Aedes albopictus. PLoS One. 2013;8(7):e68836.

86. Calvo E, Mans BJ, Andersen JF, Ribeiro JMC. Function and evolution of a mosquito salivary protein family. J Biol Chem. 2006;281:1935-42.

87. Drame PM, Poinsignon A, Besnard P, Cornelie S, le Mire J, Toto JC, et al. Human antibody responses to the Anopheles salivary gSG6-P1 peptide: A novel tool for evaluating the efficacy of ITNs in malaria vector control. PLoS One. 2010;5:1-8.

88. King JG, Vernicks KD, Hillyer JF. Members of the salivary gland surface protein (SGS) family are major immunogenic components of mosquito saliva. J Biol Chem. 2011;286:40824-34.

89. Sun L, Zeng X, Yan C, Sun X, Gong X, Rao Y, et al. Crystal structure of a bacterial homologue of glucose transporters GLUT1-4. Nature. 2012;490:361-6.

90. Overend G. Drosophila as a model for the Anopheles Malpighian tubule. PhD thesis. University of Glasgow; 2010.

91. Zollner GE, Ponsa N, Garman GW, Poudel S, Bell JA, Sattabongkot J, et al. Population dynamics of sporogony for Plasmodium vivax parasites from western Thailand developing within three species of colonized Anopheles mosquitoes. Malar J. 2006;5:68.

92. Sato Y, Montagna GN, Matuschewski K. Plasmodium berghei sporozoites acquire virulence and immunogenicity during mosquito hemocoel transit. Infect Immun. 2014:82:1164-72 
93. Altschul SF, Madden TL, Schäffer AA, Zhang J, Zhang Z, Miller W, et al. Gapped BLAST and PSI-BLAST: a new generation of protein database search programs. Nucleic Acids Res. 1997;25:3389-402.

94. Bateman A, Birney E, Cerruti L, Durbin R, Etwiller L, Eddy SR, et al. The Pfam protein families database. Nucleic Acids Res. 2002;30:276-80.

95. Kanamori Y, Saito A, Hagiwara-Komoda Y, Tanaka D, Mitsumasu K, Kikuta S, et al. The trehalose transporter 1 gene sequence is conserved in insects and encodes proteins with different kinetic properties involved in trehalose import into peripheral tissues. Insect Biochem Mol Biol. 2010;40:30-7.

96. Joost HG, Thorens B. The extended GLUT-family of sugar/polyol transport facilitators: nomenclature, sequence characteristics, and potential function of its novel members (review). Mol Membr Biol. 2001;18:247-56.

97. Joost H, Bell Gl, Best JD, Birnbaum MJ, Charron MJ, Chen YT, et al. Nomenclature of the GLUT/SLC2A family of sugar/polyol transport facilitators. Am J Physiol Endocrionl Metab. 2002;282:E974-6.

98. Uldry M, Thorens B. The SLC2 family of facilitated hexose and polyol transporters. Pflugers Arch. 2004;447:480-9.

99. Kikuta S, Kikawada T, Hagiwara-Komoda Y, Nakashima N, Noda H. Sugar transporter genes of the brown planthopper, Nilaparvata lugens: A facilitated glucose/fructose transporter. Insect Biochem Mol Biol. 2010;40:805-13.

100. Moller S, Croning M, Apweiler R. Evaluation of methods for the prediction of membrane spanning regions. Bioinformatics. 2001;17:646-53.

101. Maestro, version 9.1 (2010) Schrödinger, LLC, New York, NY.

\section{Submit your next manuscript to BioMed Central and take full advantage of:}

- Convenient online submission

- Thorough peer review

- No space constraints or color figure charges

- Immediate publication on acceptance

- Inclusion in PubMed, CAS, Scopus and Google Scholar

- Research which is freely available for redistribution 